\title{
ACEITAR OU REJEITAR? EIS A QUESTÃO DOS TIPOS DE ARGUMENTOS PARA A JUSTIFICATIVA DE ARTIGOS EM ADMINISTRAÇÃO
}

\author{
ACCEPT OR REJECT? THE ISSUE OF THE TYPES OF ARGUMENTS FOR THE REA- \\ SONING OF ARTICLES IN ADMINISTRATION
}

Recebido em: 03/08/2018 • Aprovado em: 27/11/2018

Avaliado pelo sistema double blind review

Editor Científico: Edson Sadao Iizuka

DOI 10.13058/raep.2019.v20n1.1222

\section{ALESSANDRO PRUDÊNCIO LUKOSEVICIUS alessanpl@gmail.com}

\author{
UNIVERSIDADE DO GRANDE Rio
}

\section{JAIRO DE CARVALHO GUIMARÃES}

Universidade Federal do Piauí

\section{DEBORAH MORAES ZOUAIN}

UNiVERSIDADE DO GRANDE Rio

\section{RESUMO}

A relevância do estudo tem sido reconhecida como principal fator de rejeição ou aceitação de artigos pelos editores de periódicos. Assim, justificar o estudo de maneira clara e persuasiva é um conhecimento preponderante para os pesquisadores. Todavia, apesar da importância, os manuais de pesquisa tratam, de forma superficial, a apresentação da relevância de uma pesquisa. Desse modo, o objetivo deste artigo é identificar os tipos de argumentos empregados para justificar as pesquisas científicas em Administração. Para obter a resposta, empregou-se pesquisa exploratória implementada por métodos mistos (triangulação concomitante). Como resultado, foram identificados seis tipos de argumentos empregados por artigos na área de Administração: argumentos de autoridade, escassez, contribuição teórica, necessidade, contribuição prática e lacuna.

Palavras-chave: Classificação Hierárquica Descendente. Justificação. Relevância. Triangulação.

\footnotetext{
ABSTRACT

The relevance of the study has been recognized as the main factor of rejection or acceptance of articles by journals editors. Thus, justifying the study in a clear and persuasive way is a preponderant knowledge for the researchers. However, despite the importance, the research manuals superficially treat the presentation of the relevance of a research. Thus, the objective of this article is to identify the types of arguments used to justify scientific research inAdministration. To obtain the answer, we used exploratory research implemented by mixed methods (concomitant triangulation). As a result, six types of arguments were identified for articles in the Administration area: authority arguments, scarcity, theoretical contribution, necessity, practical contribution and gap.

Keywords: Hierarchical Rating Descending. Justification. Relevance. Triangulation.
} 


\section{INTRODUÇÃO}

A produção de conhecimento científico cresce exponencialmente devido, por exemplo, ao emprego de tecnologia da informação e ao advento das bases de dados indexadoras (MERUANE; BALIN, 2012). Tal recrudescimento da produção científica, notadamente no campo da Administração, tem influenciado diretamente no processo de desenvolvimento de pesquisas no Brasil.

Esse fato impõe aos pesquisadores, estudiosos, especialistas e docentes em geral uma busca permanente por eventos que concedam o devido espaço para a apreensão e o desvelamento de trabalhos recém-produzidos. No Brasil, tais movimentos estão sendo catalisados pelos incentivos meritocráticos e classificatórios dos órgãos fomentadores de pesquisa, tais como a CAPES e o CNPQ.

Ademais, no campo da Administração, a preocupação com o rigor e a relevância da pesquisa nacional é fator de discussão recorrente na literatura e nos encontros da comunidade científica nacional (BERTERO et al., 2013), tal como o EnANPAD - Encontro da Associação Nacional de Pós-Graduação e Pesquisa em Administração. Nesse contexto, também se assentam as discussões sobre a necessidade de a Administração aproximar dos praticantes (REBECCA, 2010) e, dessa forma, se fortalecer como ciência social aplicada. Os argumentos que revelam a relevância do estudo são, normalmente, retratados na justificativa da pesquisa.

Neste sentido, vale destacar que a falta de relevância (contribuição de valor) do estudo para a ciência e para o conhecimento é o principal fator na decisão de aceitação ou rejeição de artigos pelos editores de periódicos (FALASTER; FERREIRA; CANELA, 2016). Segundo os autores, isso ocorre porque falhas técnicas podem ser corrigidas, mas um artigo sem contribuição não apresentará grandes melhoras nas rodadas vindouras de revisão.

Tal busca por espaço no cenário científico aumenta a importância da justificativa dos trabalhos em Administração, uma vez que a justificativa explica o porquê de se realizar a pesquisa (FIGUEIREDO, 2008). Assim, a justificativa visa a convencer o leitor acerca da necessidade e relevância 
da pesquisa proposta (HADDAD, 2004; CAJUEIRO, 2015) aumentando a aceitação dos mesmos na ciência nacional e internacional.

Todavia, apesar do rigor e da relevância serem as bases de um trabalho científico significativo, as práticas científicas têm privilegiado o rigor em detrimento da relevância, principalmente no campo da Administração (MASCARENHAS; ZAMBALDI; MORAES, 2011). Então, existe a necessidade de se reequilibrar as prioridades no campo da Administração dando-se foco ao aprimoramento da relevância e sua formulação por meio de elementos racionais e persuasivos. Neste trabalho, entende-se por argumento "[...] qualquer razão, prova ou demonstração capaz de obter o assentimento e de induzir persuasão ou convicção" (ABBAGNANO, 2012, p. 90) e argumentação como sendo: “[...] uma combinação entre diferentes componentes, que exige do sujeito que argumenta construir, de um ponto de vista racional, uma explicação, recorrendo a experiências individuais e sociais, num quadro espacial e temporal de uma situação com finalidade persuasiva" (KOCH; ELIAS, 2017, p. 24).

Pelo apresentado, o objetivo deste artigo é identificar os tipos de argumentos empregados para justificar as pesquisas científicas na área de Administração. Como estratégia de pesquisa, empregou-se a triangulação concorrente (CRESWELL, 2010) visando a atingir os benefícios da abordagem pelos métodos mistos (qualitativos e quantitativos) (HUSSEIN, 2009), pois, para Lahlou (1994), pode-se superar a dicotomia entre a análise quantitativa e qualitativa quando se empregam cálculos estatísticos em variáveis qualitativas do tipo texto.

Além disso, a triangulação é útil para a produção de conhecimentos em administração, campo ainda carente de maior densidade metodológica, por permitir uma aproximação e apreensão de fenômenos da realidade, de forma abrangente e aprofundada (ZAPPELLINI; FEUERSCHUTTE, 2015). Desta forma, a triangulação tem sido empregada com os propósitos de confirmação e complementação das abordagens quantitativas e qualitativas (HUSSEIN, 2009).

A abordagem quantitativa ficou por conta da Classificação Hierárquica Descendente (CHD), proposta por Reinert (1990). Para a abordagem 
qualitativa, foi aplicada a Análise de Conteúdo (AC) na visão francesa, conforme Bardin (2011). Vale ressalvar que, apesar da AC ser empregada neste trabalho como abordagem qualitativa, Minayo (2016) afirma que a mesma é flexível para se integrar a delineamentos de investigação científica qualitativos e/ ou quantitativos.

O corpus de análise foi formado pelos 33 artigos selecionados para premiação no congresso EnANPAD 2016, segundo maior evento científico de Administração no mundo (ANPAD, 2017). Como resultado, foram identificados seis tipos de argumentos empregados por artigos na área de Administração, em ordem decrescente de ocorrências: argumentos de autoridade, escassez, contribuição teórica, necessidade, contribuição prática e lacuna. 


\section{REFERENCIAL TEÓRICO}

Para Mello (2017), o valor de uma pesquisa está no contexto e na pergunta (problema) de trabalho. Assim, um problema de pesquisa é relevante se é suficientemente importante sob o ponto de vista científico, isto é, se o problema pode oportunizar conclusões valiosas à Ciência (WALDEMAR et al., 2007).

Desse modo, torna-se importante entender as razões para a produção de conhecimento. Para Santos, Kienen e Castineira (2015), o conhecimento é produzido por três razões: questionamento, necessidade e curiosidade. Segundo os autores, a permanente dúvida move a humanidade, assim o questionamento advém da busca pelo saber. Já a necessidade de sobrevivência levou o homem a criar ferramentas, mecanismos e sistemas de produção. Por fim, a curiosidade leva o homem a explorar o desconhecido no sentido de desvelar a lógica da natureza. Por conseguinte, os argumentos da justificativa científica deveriam se relacionar com as três razões elencadas.

Para Rebecca (2010), é importante medir o impacto de uma pesquisa de formas que vão além das citações. Grant et al. (2009) entendem o impacto em pesquisa como possíveis benefícios gerados pela pesquisa nas esferas econômica, social, ambiental e cultural para uma comunidade ampla. Assim, a justificativa da pesquisa aparenta estar intimamente relacionada com: (1) as razões para se empreender a pesquisa, isto é, os problemas e as oportunidades que serão abordados pela pesquisa e (2) os benefícios consequentes de se empreender o esforço da pesquisa.

Nessa direção, o rigor (teórico e metodológico) e a relevância (contribuição de valor) são apontados como fundamentos para se produzir um trabalho científico de qualidade (BACHARACH, 1989; WHETTEN, 1989; PENDERGAST, 2007; MASCARENHAS; ZAMBALDI; MORAES, 2011). Para Serra, Fiates e Ferreira (2008, p. 39), contribuição de valor significa "[...] estender a teoria para demonstrar novos antecedentes, novas consequências, novas relações mediadoras, etc". Todavia, apesar de muitos pesquisadores referenciarem a ideia de relevância, são poucos os que sabem o que isso realmente significa (NICOLAI; SEIDL, 2010). 
Desta forma, na justificativa de um trabalho científico deveria-se: (1) apresentar os benefícios esperados com o estudo, assim como a importância de se fazer o estudo neste momento (FIGUEIREDO, 2008; CAJUEIRO, 2015; COOPER; SCHINDLER, 2016) e (2) demonstrar que a pesquisa é atual, original, relevante, viável, útil e necessária (BORGES, 2013). Assim, a justificativa da pesquisa deve ser calcada em evidências, tais como fatos, estatísticas, exemplos, ilustrações (MELLO, 2017).

Na literatura científica, diversos autores mencionam a relevância em termos de contribuição teórica (científica) e (ou) prática (social) (PENDERGAST, 2007; FIGUEIREDO, 2008; VASCONCELOS, 2009; MASCARENHAS; ZAMBALDI; MORAES, 2011; LAKATOS; MARCONI, 2017). Aliás, nem se exige que o trabalho tenha múltiplas contribuições (SERRA; FIATES; FERREIRA, 2008), basta uma que seja útil para a teoria, prática ou ambas (PENDERGAST, 2007).

A relevância teórica (científica) ocorre quando o conhecimento é pertinente para a evolução dos conhecimentos ou procedimentos científicos (MASCARENHAS; ZAMBALDI; MORAES, 2011). Por exemplo, quando (PENDERGAST, 2007; MATTOS, 2008; BORGES, 2013; FERREIRA, 2015; BARRAL, 2016; VOLPATO, 2017): (1) originar novos conhecimentos. No entanto, originalidade está mais ligada à forma como se aborda um tema do que o tema em si; (2) abrir possibilidades de pesquisa em novas áreas, e (3) surpreender, criticar, fomentar ou contestar suposições anteriores que é o caso de estudos contraintuitivos (aqueles que desafiam a sabedoria popular) ou paradoxais (aqueles que levam a resultados inesperados, por exemplo, em face da teoria devia ser X, no entanto é Y) e (4) identificar uma lacuna de conhecimento (isto é, aquilo que não está bem esclarecido, bem entendido e necessita de pesquisas com maior profundidade e extensão).

Nesse sentido, Ferreira, Pinto e Belfort (2016), ao explicarem o que constitui uma revisão construtiva de um artigo em Administração, comentam que o revisor de artigo em periódico deve ajudar a identificar qual aspecto do artigo pode fazer diferença como contribuição ou novidade. Assim, identificar claramente a relevância do estudo contribui com o trabalho dos revisores. 
A relevância prática (social) refere-se a quanto o conhecimento gerado impacta a sociedade e a economia (VASCONCELOS, 2009). Afinal, a pesquisa é um empreendimento social e sua importância deve ser ressaltada num contexto mais amplo (HADDAD, 2004). Assim, a relevância de um texto científico é atribuída pelos membros de uma comunidade (científica e não científica) por meio do consenso social em torno da importância e pertinência do problema tratado (MASCARENHAS; ZAMBALDI; MORAES, 2011).

Ademais, a Administração, como Ciência Social Aplicada, exige uma relevância prática (NICOLAI; SEIDL, 2010), isto é, a conversão do que se auferiu enquanto pesquisa em modelos funcionais, reconhecidamente aplicáveis. Por exemplo, quando (MATTOS, 2008; BARRAL, 2016): (1) atrair a atenção de audiências na comunidade e (2) contribuir para o debate na sociedade.

Em continuidade, Meruane e Balin (2012) definem os tipos de justificativas:

- Falta de conhecimento genérico: se argumenta que existe uma carência genérica de conhecimento em uma área

- Falta de conhecimento prático: se sustenta que não se conhece o resultado da aplicação de um conhecimento estabelecido em outras condições (zonas geográficas, sujeitos, etc);

- Baseada na importância da questão: se argumenta que a questão a investigar é importante por suas implicações científicas, sociais ou econômicas;

- Baseado na contribuição dos achados: se justifica a investigação pelas contribuições (as aplicações) que podem implicar os achados;

- Baseado em um lacuna metodológica: se justifica a investigação pela utilização de um método novo que dá novas luzes sobre uma questão;

- Baseado na solução de um problema: a investigação se baseia na resolução de um problema não resolvido de forma satisfatória, e 
- Baseada na corroboração empírica de uma teoria: a investigação se justifica enquanto se tenta corroborar empiricamente uma teoria.

Assim, na literatura científica percebe-se uma preocupação dos autores com a importância da justificativa da contribuição de valor dos trabalhos, uma vez que sem relevância um estudo não deveria ser empreendido. Por conseguinte, dado que a Ciência anseia por novidades, evidencia-se a necessidade da justificativa propor algo novo, em termos teóricos e práticos, de forma incremental ou radical.

Por fim, Mitchell e Clark (2018, p. 3) atestam que "[...]a vida é curta demais para escrever mal. Os leitores não precisam disso, e os escritores de pesquisa qualitativa não devem fazer parte desse crime.”. Para os autores, existem cinco etapas para redigir pesquisas qualitativas mais envolventes: (1) considere o que você está escrevendo: os acadêmicos também têm muitas vozes: o trabalho de pesquisa, o pedido de subsídio, o tweet, a revisão do periódico, o livro didático, a dissertação e o editorial. A escrita bem-sucedida requer que um escritor preste atenção, diligente e silenciosa, à construção do gênero em que está trabalhando. Cada gênero tem seu próprio senso de verossimilhança - o significado da verdade; (2) identifique a quem você escreve: "quem é o meu público?" Identifique as preocupações, o histórico e a receptividade mais prováveis ao que você está escrevendo. Só então você pode começar a escrever com essa conexão em mente. (3) persuada: como ensinado por Aristóteles, a persuasão é a base para o envolvimento e influência. Para ele, os escritores devem usar meios diferentes para persuadir os leitores: logos, a solidez da lógica; ethos, conexão emocional com a mensagem; e pathos, crença de que quem persuade tem autenticidade emocional e credibilidade moral. A integração do gênero, da audiência e do carisma persuasivo é essencial ao escrever manuscritos convincentes para públicos menos familiarizados com a pesquisa; (4) encontre sua voz e cadência: conheça as regras e convenções para saber como "desrespeitá-las" e crie seu estilo de escrita; (5) Tome riscos criativos: criatividade na escrita acadêmica dá forma a ideias usando originalidade e inova- 
GUIMARÃES \& DEBORAH MORAES ZOUAIN

ção, conforme definido por um contexto social. Em pesquisas que podem significar criatividade metodológica, tome emprestada uma convenção de escrita de outra disciplina, ou combine ideias aparentemente diversas para criar um todo novo. 


\section{PROCEDIMENTOS METODOLÓGICOS}

Este artigo visa a identificar os tipos de argumentos empregados na justificativa de pesquisas científicas na área de Administração. Assim, optou-se por pesquisa exploratória, pois desejou-se explicitar um problema tornando-o mais familiar (GIL, 2010). Ademais, foram empregados métodos mistos (quantitativos e qualitativos) implementados por meio de triangulação concomitante (CRESWELL, 2010).

Há de se destacar que existe um aumento de interesse na pesquisa que utiliza métodos mistos, os quais estão sendo aplicados a muitos campos de pesquisa (CRESWELL, 2010). Uma forte razão é que os métodos mistos permitem maximizar pontos fortes e minimizar pontos fracos das abordagens qualitativa e quantitativa e obter uma maior compreensão do problema de pesquisa (CRESWELL, 2010). As abordagens qualitativa e quantitativa diferenciam-se na forma de solucionar o problema, a primeira busca entendimento holístico e integrado, enquanto a segunda busca segurança e mais precisão na análise (RICHARDSON, 2010).

Nesta direção, os métodos mistos demandam alguma forma de triangulação. Desse modo, a triangulação é empregada para ampliar e aprofundar o entendimento sobre o estudo do fenômeno, assim como aumentar a acurácia, validade e credibilidade do estudo (HUSSEIN, 2009). Corrobora Dang (2015), ao afirmar que a triangulação é uma estratégia para combinar as vantagens da abordagem qualitativa e quantitativa, e para aumentar a validade dos resultados da avaliação e da pesquisa. Zappellini e Feuerschutte (2015, p. 246) definiram triangulação como: “[...]procedimento que combina diferentes métodos de coleta e de análise de dados, diferentes populações/sujeitos (ou amostras/objetos), diferentes perspectivas teóricas e diferentes momentos no tempo, com o propósito de consolidar suas conclusões a respeito do fenômeno que está sendo investigado."

Creswell (2010) recomenda quatro critérios para escolher uma estratégia de métodos mistos adequada: distribuição de tempo, atribuição de peso, tipo de combinação e teorização. A distribuição de tempo indica se a coleta de dados (qualitativos e quantitativos) será concomitante (ao mesmo 
tempo) ou sequencial (em fases). A atribuição de peso refere-se a prioridade dada para a abordagem, podendo priorizar a abordagem qualitativa, quantitativa ou ser igual para ambas. O tipo de combinação está relacionado a como os dados da pesquisa serão combinados, podendo ser: (1) integrados: juntar os dados qualitativos e quantitativos, (2) conectados: combinar os dados de uma fase com os dados de outra fase ou (3) incorporados: incorporar uma fonte secundária de dados a uma fonte primária maior. A teorização força o questionamento se uma perspectiva teórica maior guiará o estudo, além de definir se será explícita (mencionada) ou implícita (não mencionada).

Assim, os quatro critérios foram definidos neste estudo: em relação a distribuição de peso, os dados quantitativos e qualitativos foram coletados concomitantemente (uma vez que derivam do mesmo corpus de análise), a atribuição de peso foi igual para ambas as abordagens, o tipo de combinação foi de dados integrados e a teorização foi implícita.

Como delineamento geral de pesquisa, adotou-se a triangulação denominada triangulação concomitante. Para Creswell (2010), a triangulação concomitante é vantajosa por ser familiar a muitos pesquisadores, além de levar normalmente a resultados validados e substanciados. Nesse tipo de triangulação, os métodos quantitativos e qualitativos são aplicados separadamente para permitir posterior comparação dos resultados para a interpretação conjunta, conforme Figura 1. 
Figura 1 Esquema da pesquisa com o delineamento triangulação concomitante

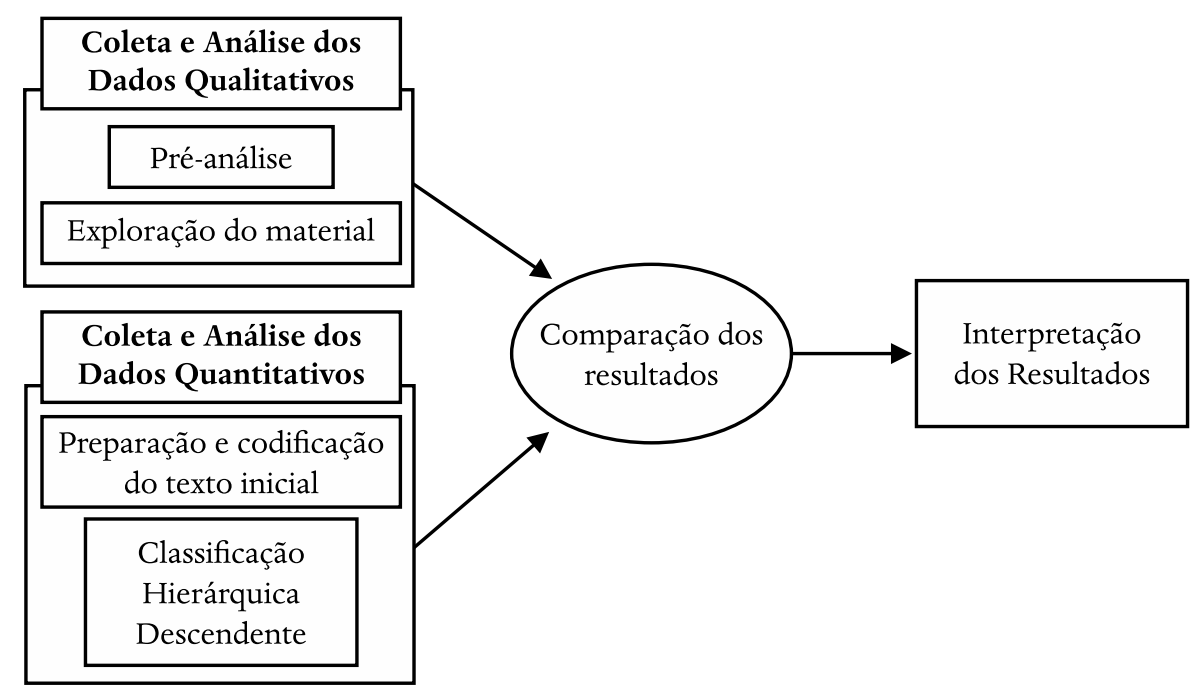

Fonte: Elaborada pelos autores, 2018.

A Análise de Conteúdo (AC) é um método formado por um conjunto de técnicas (categorial, de avaliação, da enunciação, da expressão, das relações, do discurso) de análise das comunicações que utiliza procedimentos sistemáticos e objetivos de descrição e/ou predição do conteúdo das mensagens manifestas (explícitas) e latentes (ocultas) por meio de indicadores quantitativos e/ ou qualitativos (BARDIN, 2011; MINAYO, 2016). No esquema da pesquisa, a coleta e análise dos dados qualitativos respeitou os dois primeiros passos pela visão francesa da AC proposta por Bardin (2011): (1) pré-análise: passo encarregado de organizar o corpus de análise e (2) exploração do material: passo encarregado da análise em si.

A pré-análise da AC se iniciou com a constituição do corpus de análise formado pelos 33 artigos do EnANPAD 2016 selecionados para premiação no congresso, sendo esse o critério de inclusão dos artigos no corpus. Os artigos podem ser acessados pelo site do congresso (ANPAD, 2017) e em cada um buscou-se detectar a presença de elementos de justificativa científica nas seções de Resumo e Introdução onde, em geral, a justificativa é 
apresentada. A escolha pelo EnANPAD ocorreu porque esse congresso é considerado o segundo maior evento científico de Administração do mundo, área foco deste estudo (ANPAD, 2017).

Em seguida, definiu-se a grade para análise, isto é, o tipo de abordagem para identificação das categorias e análise dos materiais. A grade escolhida para a análise foi do tipo indutiva com categorias definidas a posteriori, isto é, à medida que o pesquisador vai explorando o material de análise. Essa grade é recomendada para pesquisas exploratórias (VERGARA, 2015) como é o caso deste trabalho.

Em relação ao passo de exploração do material, o critério de classificação das categorias foi baseado em itens do tipo artigos (documentos completos), a unidade de registro foi temática e a unidade de contexto foi o parágrafo. Desta forma, procurou-se respeitar no sistema de categorias os seguintes requisitos: validade, exaustividade, homogeneidade, exclusividade, objetividade e pertinência (MORAES, 1999; BARDIN, 2011).

Com o propósito de responder a questão de pesquisa, as categorias foram descritas tendo por referência as unidades de registro (MORAES, 1999) e os resultados analisados pela justaposição das categorias (SILVA; FOSSA, 2013). Por fim, empregou-se o software Atlas.ti como apoio da AC e foram mencionadas expressões retiradas dos artigos para ilustrar cada tipo de argumento, medidas que aspiraram aumentar a confiabilidade da pesquisa.

O método quantitativo empregado na pesquisa foi a Classificação Hierárquica Descendente (CHD). A CHD é um método de análise estatística multivariada que possibilita a análise de material textual provendo contextos organizados por classes lexicais constituídas com base em segmentos de textos de um vocabulário (CAMARGO; JUSTO, 2013a). Assim, os segmentos de texto se aglutinam em classes com vocabulário semelhante e diferente do encontrado em outras classes. No esquema da pesquisa, a coleta e análise dos dados quantitativos respeitou os dois primeiros passos propostos por Lahlou (1994) para a CHD: (1) passo responsável pela preparação e codificação do texto inicial e (2) passo que aplica a classificação hierárquica descendente em si. 
Em relação a preparação e codificação do texto inicial, o corpus de análise foi o mesmo construído para a $\mathrm{AC}$, porém teve que ser reorganizado para atender a CHD, conforme as recomendações de Camargo e Justo (2013b): (1) rastrear erros de digitação para não serem entendidos como palavras diferentes; (2) eliminar o espaço entre os textos não deixando parágrafos; (3) não justificar o texto, nem usar negrito, nem usar itálico ou outro recurso semelhante; (4) definir e padronizar as siglas: ou no formato de sigla ou por extenso separado por underline; (5) substituir o hífen por underline. Exemplo: trocar "terça-feira" por "terça_feira"; (6) passar os verbos que utilizem pronomes para a forma de próclise. Exemplo: escrever "me tornei" no lugar de "tornei-me"; (7) manter os números na forma de algarismos. Exemplo: "2013" e não "dois mil e treze"; (8) eliminar os caracteres: aspas (“), apóstrofo ('), hífen (-), cifrão (\$), percentagem (\%), reticências (...) e asterisco $\left(^{\star}\right)$. Além disso, o corpus foi dividido em duas partes, textos em português e inglês, devido a necessidade de processamento separado pelo software de apoio.

Para realizar as análises lexicais, contou-se com o apoio do software IRAMUTEQ (CAMARGO; JUSTO, 2013b). Inicialmente, o software identifica as hapax (palavras com frequência um), calcula a quantidade de palavras e a frequência média delas. Depois, reformata as unidades de texto, acessa o vocabulário com o objetivo de identificar as formas reduzidas (raízes) das palavras e cria o dicionário a partir das formas reduzidas. Por fim, por meio de repetidos testes qui-quadrado $\left(\mathrm{x}^{2}\right)$, obtêm-se uma classificação estável com formas ativas e suplementares. O procedimento detalhado para a implementação da triangulação concomitante é expressado no Quadro 1. 


\section{GUIMARÃES \& DEBORAH MORAES ZOUAIN}

Quadro 1 Procedimento para implementação da triangulação concomitante

\begin{tabular}{|c|c|}
\hline $\begin{array}{c}\text { Etapas do } \\
\text { procedimento }\end{array}$ & Explicação da etapa \\
\hline $\begin{array}{l}\text { Pré-análise da Análise } \\
\text { de Conteúdo }\end{array}$ & $\begin{array}{l}\text { Visa a organizar o corpus de pesquisa em termos } \\
\text { de selecionar o material, definir o tipo de grade } \\
\text { de análise e elaborar o esquema de codificação } \\
\text { (abordagem qualitativa) }\end{array}$ \\
\hline $\begin{array}{l}\text { Exploração do } \\
\text { material da Análise de } \\
\text { Conteúdo }\end{array}$ & $\begin{array}{c}\text { Envolve identificar as unidades de registro e contexto, } \\
\text { codificar e categorizar as informações, além de } \\
\text { descrever as categorias (abordagem qualitativa) }\end{array}$ \\
\hline $\begin{array}{l}\text { Preparação e } \\
\text { codificação do texto } \\
\text { inicial para a CHD }\end{array}$ & $\begin{array}{c}\text { Envolve preparar o texto para aplicação da } \\
\text { Classificação Hierárquica Descendente (CHD) } \\
\text { (abordagem quantitativa) }\end{array}$ \\
\hline $\begin{array}{l}\text { Classificação } \\
\text { Hierárquica } \\
\text { Descendente }\end{array}$ & $\begin{array}{c}\text { Envolve aplicar a CHD ao corpus de texto em } \\
\text { português e aplicar a CHD ao corpus de texto em } \\
\text { inglês (abordagem quantitativa) }\end{array}$ \\
\hline $\begin{array}{l}\text { Comparação dos } \\
\text { resultados }\end{array}$ & $\begin{array}{c}\text { Consiste em comparar os resultados advindos das } \\
\text { abordagens qualitativa e quantitativa }\end{array}$ \\
\hline $\begin{array}{l}\text { Interpretação dos } \\
\text { resultados }\end{array}$ & $\begin{array}{c}\text { Consiste em dar significado aos resultados } \\
\text { comparados da pesquisa }\end{array}$ \\
\hline
\end{tabular}

Fonte: Elaborado pelos autores, 2018. 


\section{RESULTADOS}

Tendo como base os 33 artigos selecionados para premiação no congresso EnANPAD 2016, constituiu-se um corpus de análise formado pelos segmentos de texto contendo os argumentos empregados para justificar cientificamente os trabalhos. Esse corpus serviu de referência para a AC e a CHD, no caso da CHD foi necessário subdividir o corpus de acordo com a língua utilizada no texto (português e inglês) e processá-los separadamente.

\section{ANÁLISE DE CONTEÚDO DO CORPUS DE ANÁLISE}

Inicialmente, realizou-se uma leitura geral do corpus de análise para se entender como os artigos estavam organizados. Assim, procurou-se manter a divisão sugerida pela EnANPAD em que os 33 artigos foram organizados em 11 divisões, portanto, três artigos por divisão (ANPAD, 2017): ADI Administração da Informação; APB - Administração Pública; CON - Contabilidade; EOR - Estudos Organizacionais; EPQ - Ensino e Pesquisa em Administração e Contabilidade; ESO - Estratégia em Organizações; FIN Finanças; GCT - Gestão de Ciência, Tecnologia e Inovação; GOL - Gestão de Operações e Logística; GPR - Gestão de Operações e Relações de Trabalho; MKT - Marketing. Além disso, criou-se uma seção com os vencedores de cada divisão, assim como uma seção contendo apenas o melhor artigo do evento. Portanto, foram analisados os artigos sob a ótica de 13 divisões. O Anexo A numera os 33 artigos para facilitar a referência dos trechos de textos ilustrativos dos tipos de argumento.

Com o apoio do software Atlas.ti, a codificação e categorização dos códigos foi realizada. Assim, foram identificadas seis categorias que representam os tipos de argumentos: (1) Argumentos de autoridade, (2) Escassez, (3) Contribuição teórica, (4) Necessidade, (5) Contribuição prática e (6) Lacuna. As seis categorias correspondem aos seis tipos de argumentos empregados pelos autores nos 33 artigos pesquisados.

Em seguida, as categorias foram descritas e ilustradas com textos retirados dos artigos. Além disso, foram identificadas quais categorias estavam presentes em cada uma das 13 divisões do EnANPAD 2016, bem como a 
presença das mesmas nos artigos vencedores de cada divisão e no artigo vencedor do congresso.

O tipo de argumento denominado argumentos de autoridade constituiu uma categoria em que se usa argumentos baseados na literatura científica passada ou recente, referenciando-se tanto estudos clássicos quanto estudos no estado da arte, conforme demonstrado nas expressões: "Evidencia-se nos últimos anos na área acadêmica..." (artigo 2) e "...a literatura recente ressalte..." (artigo 24).

Outro artifício empregado nesse tipo de argumento foi mostrar a direção que os estudos têm tomado, e assim sinalizando que o trabalho encontra-se alinhado com essa direção, por exemplo, por meio de expressões como: “...tema em expansão" (artigo 32), “...tem ganhado cada vez mais espaço nas pesquisas acadêmicas" (artigo 32), "A importância do tema..." (artigo 14), "Firms can no longer escape the effects of..." (artigo 15), “...um vertiginoso aumento na adoção..." (artigo 15), "Os [...] vêm se popularizando..." (artigo 15) e "The discussion is of particular interest for..." (artigo 8).

Outra estratégia empregada neste tipo de argumento foi mostrar que os autores estão divididos sobre determinado tema ou abordagem. Com isso, não há consenso e existe controvérsia, então a estratégia consistia em mostrar que o caminho que o estudo propunha era um dos possíveis. Manifestações desse tipo de argumento podem ser notadas nas expressões: "Despite the interest..." (artigo 3) e "Diante desse debate, ..." (artigo 16). Uma variação dessa estratégia foi listar os argumentos diretamente da literatura científica para tentar estabelecer robustez na justificativa, como demonstrado em: "The main contribution of this study is supported by three main findings in literature." (artigo 26), "Outro exemplo é..." (artigo 2) e "Investigar [...] é importante pela...” (artigo 4).

O tipo de argumento denominado escassez parte do entendimento que existem estudos sobre o tema ou problema pesquisado, no entanto, esses estudos são considerados incompletos em algum grau, como demonstrado pelas expressões: “...very few studies [...] cope with...” (artigo 13), "Pouco se sabe..." (artigo 9), "poucas pesquisas têm se debruçado sobre..." 
(artigo 10), “...has focused less on..." (artigo 11) e “...sejam pouco exploradas pela literatura." (artigo 32).

Outra estratégia nesse tipo de argumento foi mostrar que apesar de muitos estudos abordarem um determinado tema, existe um aspecto particular no objeto de estudo que o torna diferenciado, como demonstrado pelas expressões: "Apesar da ampla literatura neste campo [...] não são muito reportados." (artigo 23), "Most of the literature [...] addressed the [...]. However, there are few theoretical definitions [...] that address..." (artigo 6), "This discussion is of particular interest for..." (artigo 8), "Este trabalho visa complementar...” (artigo 21) e "...pouca atenção é dada...” (artigo 25).

O tipo de argumento denominado contribuição teórica foca-se em mostrar que a pesquisa contribui para a literatura científica como demonstrado pelas expressões: "Esta pesquisa contribui com os estudos sobre..." (artigo 23), "This study offers a singular contribution to the export literature." (artigo 15), "Com o intuito de avançar teoricamente..." (artigo 25), "...para aprofundar questões importantes para a construção de pesquisas..." (artigo 2), “...a presente pesquisa avança na literatura..." (artigo 18), "Assim, contribuímos empiricamente testando..." (artigo 17) e "...we empirically tested our conceptual model...” (artigo 15), “...propondo maior reflexividade para os estudos..." (artigo 10), "...além de ampliar os recentes debates..." (artigo 31) e "...os debates conclamam os pesquisadores a repensar..." (artigo 29).

No tipo de argumento denominado necessidade, a ideia de necessidade está associada em mostrar a importância do estudo para a academia, economia ou sociedade, como demonstrado nas expressões: "Sua importância está em...” (artigo 33), “...reconhecem cada vez mais a necessidade de...” (artigo 12) e “...torna-se necessário...” (artigo 28).

Por contribuição prática se nomeia o tipo de argumento ligado à contribuição gerencial no sentido de solucionar problemas, fomentar desenvolvimentos e aprimorar processos como constatado pelas expressões: “...essa pesquisa contribui para gestores...” (artigo 9), “...uma contribuição gerencial..." (artigo 23), "Este artigo investiga métodos para solucionar problemas..." (artigo 5), "O objetivo deste estudo é buscar [...] fomentar o 
desempenho...” (artigo 31), “...seeking to reduce the...” (artigo 8), “...pode trazer implicações no processo de..." (artigo 28) e “...contribuem para o desenvolvimento de..." (artigo 28).

Por fim, lacuna foi o tipo de argumento que relata um vazio na literatura, principalmente relacionado a uma lacuna de: conhecimento, empírica ou em relação à literatura científica brasileira. Vale dizer que o sentido de vazio é no sentido de não ter estudado o problema com a profundidade requerida ou sob determinado enfoque, e não no caso de necessariamente nunca o ter estudado. Algumas expressões que demonstram esse tipo de argumento foram: “...mas ainda existe uma lacuna na...” (artigo 9), "Não tendo sido identificado na literatura brasileira pesquisas que..." (artigo 10), “...a literatura apresenta lacunas de conhecimentos sobre..." (artigo 31), “... there has been no empirical analysis..." (artigo 3), "...apresenta uma lacuna teórica sobre..." (artigo 25) e "...não se conhece nenhum estudo que..." (artigo 4).

Vale destacar que foram encontradas seções Resumo e Introdução, dentre os 33 artigos pesquisados, sem nenhum argumento de justificativa da pesquisa, tendo o número de Resumos (27\%) sem justificativas superado o número de Introduções (12\%) sem justificativas. A Tabela 1 relaciona os tipos de argumentos com as 11 divisões do EnANPAD 2016, acrescido das seções de: vencedores das divisões (11 artigos) e vencedor do congresso (um artigo). Na Tabela 1, os percentuais indicam o uso do tipo de argumento por categoria, com cada argumento pode se encaixar em mais de um tipo. 
Tabela 1 Emprego dos tipos de argumentos nas divisões do EnANPAD 2016

\begin{tabular}{|c|c|c|c|c|c|c|}
\hline & 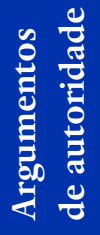 & 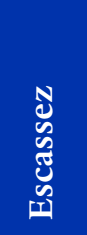 & 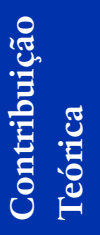 & 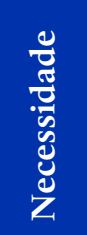 & 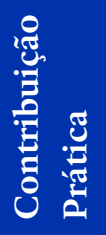 & 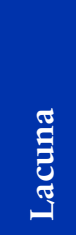 \\
\hline $\mathrm{ADI}$ & $63 \%$ & $13 \%$ & $0 \%$ & $13 \%$ & $0 \%$ & $13 \%$ \\
\hline APB & $33 \%$ & $33 \%$ & $0 \%$ & $0 \%$ & $0 \%$ & $0 \%$ \\
\hline COM & $11 \%$ & $11 \%$ & $33 \%$ & $22 \%$ & $11 \%$ & $22 \%$ \\
\hline EOR & $20 \%$ & $10 \%$ & $30 \%$ & $10 \%$ & $0 \%$ & $10 \%$ \\
\hline EPQ & $0 \%$ & $13 \%$ & $38 \%$ & $13 \%$ & $25 \%$ & $0 \%$ \\
\hline ESO & $10 \%$ & $10 \%$ & $40 \%$ & $20 \%$ & $20 \%$ & $0 \%$ \\
\hline FIN & $50 \%$ & $0 \%$ & $0 \%$ & $0 \%$ & $0 \%$ & $17 \%$ \\
\hline GCT & $33 \%$ & $22 \%$ & $11 \%$ & $0 \%$ & $33 \%$ & $11 \%$ \\
\hline GOL & $13 \%$ & $50 \%$ & $13 \%$ & $0 \%$ & $25 \%$ & $0 \%$ \\
\hline GPR & $29 \%$ & $43 \%$ & $14 \%$ & $0 \%$ & $0 \%$ & $14 \%$ \\
\hline MKT & $15 \%$ & $31 \%$ & $8 \%$ & $31 \%$ & $8 \%$ & $8 \%$ \\
\hline $\begin{array}{l}\text { Vencedores } \\
\text { das divisões }\end{array}$ & $26 \%$ & $22 \%$ & $7 \%$ & $7 \%$ & $4 \%$ & $15 \%$ \\
\hline $\begin{array}{l}\text { Vencedor } \\
\text { do congresso }\end{array}$ & $100 \%$ & $0 \%$ & $0 \%$ & $0 \%$ & $0 \%$ & $50 \%$ \\
\hline
\end{tabular}

Fonte: Elaborada pelos autores, 2018.

A partir da Tabela 1, nota-se que os tipos de argumentos que predominaram para cada divisão do EnANPAD 2016 foram: ADI - Administração da Informação com argumentos de autoridade; APB - Administração Pública com argumentos de autoridade e escassez; CON - Contabilidade com contribuição teórica; EOR - Estudos Organizacionais com contribuição teórica; EPQ - Ensino e Pesquisa em Administração e Contabilidade com contribuição teórica; ESO - Estratégia em Organizações com contribuição teórica; FIN - Finanças com argumentos de autoridade; GCT - Gestão de Ciência, Tecnologia e Inovação com argumentos de au- 
toridade e contribuição prática; GOL - Gestão de Operações e Logística com escassez; GPR - Gestão de Operações e Relações de Trabalho com escassez e MKT - Marketing com escassez e necessidade.

Por fim, tanto nos artigos vencedores das divisões quanto no artigo vencedor do congresso predominou o tipo de argumento argumentos de autoridade. Em seguida, apresentam-se os resultados da CHD para os corpus de análise em português e inglês, nesta ordem.

\section{CHD SOBRE O CORPUS DE ANÁLISE EM PORTUGUÊS}

A aplicação da CHD no corpus de análise em português gerou 76 segmentos de texto sendo 57 segmentos aproveitados pela $\mathrm{CHD}$, portanto houve $75 \%$ de retenção do corpus. Ademais, foram 2778 ocorrências de palavras, sendo 948 palavras distintas e 567 palavras com apenas uma ocorrência (hapax). Assim, a média de ocorrência por palavra foi de 2,93.

Os resultados da CHD geraram seis classes conforme dendograma da Figura 2 que mostra as classes e as relações entre elas. Para a análise descritiva de cada classe foram utilizados os dois critérios sugeridos por Camargo e Justo (2013b) para escolher em quais palavras focar: (1) palavras com frequência maior que a frequência média do conjunto de palavras do corpus. Neste caso, palavras com frequência acima de 2,93 e (2) palavras com qui-quadrado $\left(\mathrm{x}^{2}\right)$ de associação a classe igual ou superior a 3,84 , pois assim a margem de erro será inferior a 0,05 para um grau de liberdade igual a 1 (um). 
Figura 2 Dendograma da CHD do corpus de análise em português referente aos argumentos de justificativa científica dos artigos do EnANPAD 2016

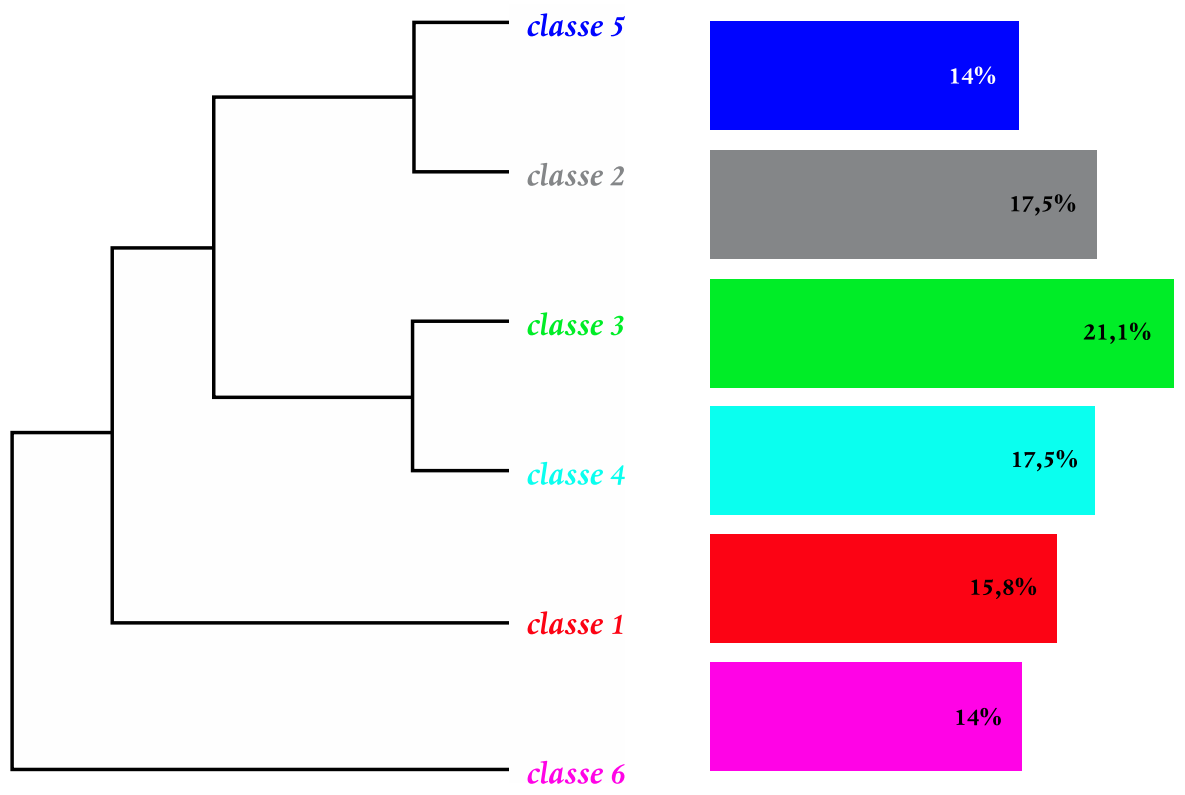

Fonte: Elaborada pelos autores, 2018.

Nota-se que o dendograma da Figura 2 foi repartido em dois subcorpus. O primeiro, formado pela classe 6 , relaciona relevância e necessidade. $\mathrm{O}$ segundo subcorpus remete a argumentação do tipo argumentos de autoridade, lacuna e escassez, além das contribuições prática e teórica, representado pelas classes 1, 2, 3, 4 e 5. Esse segundo subcorpus se dividiu novamente em dois subcorpus opondo o subcorpus contendo apenas a classe 1 ao subcorpus que contêm as classes 3 e 4 de um lado e as classes 2 e 5 do outro. As denominações das classes procuraram seguir os mesmos termos empregados na Análise de Conteúdo.

A classe 1, denominada argumentos de autoridade, foi responsável por $15,8 \%$ dos segmentos de texto. Os principais termos associados a essa classe foram: estratégia, assim, empresa, período, também e potencial. Percebeu-se a preocupação em se sustentar que existe um caminho potencial que justifique a pesquisa. O trechoa seguir ilustra esse contexto: “[...] é tam- 
bém importante pela conhecida relação entre colaboração internacional e a relevância da produção científica resultando que o esforço de publicação internacional seja menos relevante se não estiver associado a estratégias de pesquisa baseadas em colaboração internacional” (artigo 4).

A classe 2, denominada lacuna, foi responsável por $17,5 \%$ dos segmentos de texto. Os principais termos associados a essa classe foram: organizacional, pesquisa, estudo, motivo, histórico e área. Aqui, procurou-se mostrar que a sustentação para pesquisas sobre organizações pode estar calcada na ausência de histórico de trabalhos em determinada área de estudo, principalmente no âmbito nacional. O trecho a seguir ilustra esse contexto: "[...] não se conhece nenhum estudo que mapeie as características e os impactos desta internacionalização para as pesquisas no país em termos temáticos e teóricos nem do potencial de contribuição da produção nacional deste campo em âmbito internacional” (artigo 4).

A classe 3, denominada escassez, foi responsável por $21,1 \%$ dos segmentos de texto. Os principais termos associados a essa classe foram: explorar, público, embora, saber, ensino e superior. A classe 3 relacionou-se a possibilidade da argumentação vir da exploração da literatura científica em busca de temas em que, apesar de haver algum estudo, existe o estímulo para se saber mais. O trecho a seguir ilustra esse contexto: "[...] muito pouco se sabe sobre os efeitos da economia obtida no processo de licitação sobre a celeridade da entrega dos objetos adquiridos" (artigo 24).

A classe 4, denominada contribuição prática, foi responsável por $17,5 \%$ dos segmentos de texto. Os principais termos associados a essa classe foram: valor, serviço, setor, conhecido, inovador e usuário. A classe 4 destacou o valor do conhecimento prático, principalmente inovador, como tipo de argumento para pesquisas em determinado setor. O trecho a seguir ilustra esse contexto: "[...] a identificação das capacidades necessárias para a obtenção de vantagem competitiva constituem as contribuições gerenciais" (artigo 21).

A classe 5, denominada contribuição teórica, foi responsável por $14 \%$ dos segmentos de texto. Os principais termos associados a essa classe foram: capacidade, saúde, contribuição, além, forma e proposição. Neste 
caso, a classe enfatiza a contribuição em termos de forma e/ou proposição que tenha a capacidade de ir além da teoria existente. O trecho a seguir ilustra esse contexto: "[...] enquanto as contribuições para o campo acadêmico concentram na construção do modelo de mensuração para capacidades dinâmicas em estudos de corte transversal" (artigo 21).

A classe 6, denominada necessidade, foi responsável por $14 \%$ dos segmentos de texto. Os principais termos associados a essa classe foram: aplicativo, uso, móvel, adoção, necessidade e relevante. A classe 6 mostrou que se pode argumentar alegando-se necessidade e/ou relevância de um tema ou área de pesquisa para a academia, economia ou sociedade. $\mathrm{O}$ trecho a seguir ilustra esse contexto: "[...] dessa forma a razão da escolha deste objeto de pesquisa reside na necessidade de se ampliar o conhecimento sobre o mercado de aplicativos móveis no brasil devido a seu exponencial crescimento e cenário de incentivo governamental” (artigo 14).

CHD sobre o corpus de análise em inglês

Figura 3 Dendograma da CHD do corpus de análise em inglês referente aos argumentos de justificativa científica dos artigos do EnANPAD 2016

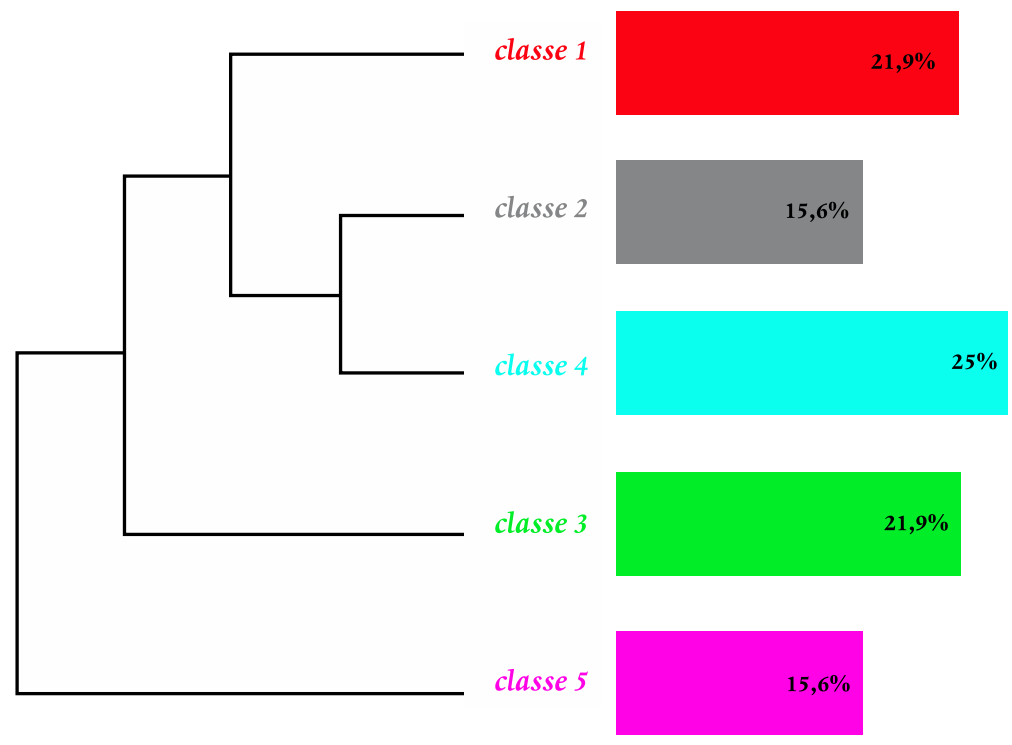

Fonte: Elaborada pelos autores, 2018. 
Observa-se que o dendograma da Figura 3 foi repartido em dois subcorpus. O primeiro, formado pela classe 5 , relacionado com a contribuição prática. O segundo subcorpus remete a argumentação do tipo lacuna, contribuição teórica, argumentos de autoridade e necessidade, representado pelas classes 1, 2, 3 e 4. Esse segundo subcorpus se dividiu novamente em dois subcorpus opondo o subcorpus contendo apenas a classe 3 ao subcorpus que contêm a classe 1 de um lado e as classes 2 e 4 do outro. Aqui, nas denominações das classes também se procurou seguir os mesmos termos empregados na Análise de Conteúdo.

A classe 1, denominada lacuna, foi responsável por $21,9 \%$ dos segmentos de texto. Os principais termos associados a essa classe foram: institutional, amount, quality, resource e investment. A classe 1 apontou que o preenchimento de lacunas no contexto corporativo, como os relacionados a qualidade, recursos e investimentos, é fonte de argumentos para a pesquisa. O trecho a seguir ilustra esse contexto: "[...] moreover they not only lack the adequate amount of resources that should be directed to knowledge intensive activities but they also suffer from endemic problems related to institutional quality" (artigo 8).

A classe 2, denominada contribuição teórica, foi responsável por $15,6 \%$ dos segmentos de texto. Os principais termos associados a essa classe foram: discussion, narcissism, study, national e topic. Na classe 2 sugeriu-se que a discussão de tópicos da teoria pode servir de argumento para o estudo. $\mathrm{O}$ trecho a seguir ilustra esse contexto: "[...] the results extend the restricted list of studies on narcissism in the national scene seeking to contribute to discussions on the diagnosis of narcissistic personalities by educators and to contribute to the improvement of educational processes" (artigo 7).

A classe 3, denominada argumentos de autoridade, foi responsável por $21,9 \%$ dos segmentos de texto. Os principais termos associados a essa classe foram: previous, behavior, examine, member e process. Assim, a classe 3 sugeriu que deve-se examinar estudos prévios em busca de argumentos para o alinhamento da pesquisa que se pretende defender. O trecho a seguir ilustra esse contexto: "[...] previous $\operatorname{lmx}$ research has primarily exam- 
ined organizational and individual out comes such as member organizational commitment performance and citizens hip behaviors" (artigo 11).

A classe 4 , denominada necessidade, foi responsável por $25 \%$ dos segmentos de texto. Os principais termos associados a essa classe foram: export, firm, economy, theoretical e emerge. Aqui, a classe 4 indicou que a necessidade ou a relevância podem emergir da teoria, economia e/ou organização. O trecho a seguir ilustra esse contexto: “[...] thus it is important to study the drivers of export activity and export performance to understand firms that have become increasingly involved in exports as a means to grow and prosper" (artigo 15).

A classe 5, denominada contribuição prática, foi responsável por $15,6 \%$ dos segmentos de texto. Os principais termos associados a essa classe foram: ownership, risk, idiosyncratic, holding e cash. A classe 5 focou em mostrar que aspectos mais concretos, como ganhos financeiros e riscos, podem municiar a argumentação científica. O trecho a seguir ilustra esse contexto: "[...] there has been no empirical analysis on the effects of the level of insider ownership on cash holdings when idiosyncratic risk is considered" (artigo 3). 


\section{ANÁLISE E INTERPRETAÇÃO DOS RESULTADOS}

Para desenvolver esse trabalho, utilizou-se triangulação concomitante, um delineamento de pesquisa que emprega métodos mistos, sendo a abordagem quantitativa representada pela Classificação Hierárquica Descendente e a abordagem qualitativa representada pela Análise de Conteúdo. O corpus de análise recaiu sobre os 33 artigos selecionados para premiação no EnANPAD 2016.

Conforme sugerido por Creswell (2010), os dados qualitativos e quantitativos podem ser comparados empregando-se uma matriz. Assim, o Quadro 2 mostra um comparativo entre os resultados revelados pela AC e CHD. Os resultados da AC foram priorizados pela ordem decrescente da frequência de ocorrência e os resultados da CHD foram priorizados pelo percentual de segmentos de texto cobertos pela classe.

Quadro 2 Priorização dos resultados da AC e da CHD em português e inglês

\begin{tabular}{|c|c|c|c|}
\hline $\begin{array}{l}\text { Priori- } \\
\text { zação }\end{array}$ & $\begin{array}{l}\text { Análise de conteúdo } \\
\text { do corpus de análise }\end{array}$ & $\begin{array}{c}\text { CHD sobre o corpus } \\
\text { de análise em } \\
\text { português }\end{array}$ & $\begin{array}{l}\text { CHD sobre o corpus } \\
\text { de análise em inglês }\end{array}$ \\
\hline 1 & $\begin{array}{l}\text { Argumentos de } \\
\text { autoridade }\end{array}$ & Escassez & Necessidade \\
\hline 2 & Escassez & Lacuna & $\begin{array}{l}\text { Argumentos de } \\
\text { autoridade }\end{array}$ \\
\hline 3 & Contribuição teórica & Contribuição prática & Lacuna \\
\hline 4 & Necessidade & $\begin{array}{l}\text { Argumentos de } \\
\text { autoridade }\end{array}$ & Contribuição prática \\
\hline 5 & Contribuição prática & Contribuição teórica & Contribuição teórica \\
\hline 6 & Lacuna & Necessidade & ---- \\
\hline
\end{tabular}

Fonte: Elaborado pelos autores, 2018.

A análise de conteúdo do corpus de análise revelou as categorias correspondentes aos tipos de argumentos: argumentos de autoridade, es- 
cassez, contribuição teórica, necessidade, contribuição prática e lacuna. A CHD sobre o corpus de análise em português revelou que as classes correspondentes aos tipos de argumentos: classe 1 (argumentos de autoridade), classe 2 (lacuna), classe 3 (escassez), classe 4 (contribuição prática), classe 5 (contribuição teórica) e classe 6 (necessidade). A CHD sobre o corpus de análise em inglês revelou como resultado as classes correspondentes aos tipos de argumento: classe 1 (lacuna), classe 2 (contribuição teórica), classe 3 (argumentos de autoridade), classe 4 (necessidade) e classe 5 (contribuição prática).

Assim, independentemente da priorização, pode-se constatar, pela análise dos resultados advindos da $\mathrm{AC}$ e da CHD, que os seis tipos de argumentos empregados na justificativa de pesquisas científicas em administração foram: argumentos de autoridade, escassez, contribuição teórica, necessidade, contribuição prática e lacuna.

O tipo de argumento argumentos de autoridade é citado por Cialdini (2006) como um dos princípios da influência, isto é, os argumentos elencados por figuras de autoridade (por exemplo, autores reconhecidos) atraem a concordância. Nesse sentido, Mello (2017) atesta que a justificativa da pesquisa deve ser calcada em evidências do tipo exemplos, referências a estudos clássicos e estudos no estado da arte. O autor também assevera que a justificativa pode ser demonstrada pelo: (1) alinhamento do estudo com a direção que os estudos têm tomado, (2) demonstração de controvérsia na literatura e (3) extração de argumentos da literatura para demonstrar robustez da justificativa.

O tipo de argumento escassez foi detectado por Meruane e Balin (2012). Os autores o denominaram de falta de conhecimento genérico no sentido de existir estudos sobre o tema ou problema pesquisado, no entanto, esses estudos são considerados incompletos em algum grau. Portanto, escassez não é ausência de conhecimentos sobre o assunto, mas a insuficiência de conhecimentos em relação a necessidade de uma comunidade científica. A escassez também é citada por Cialdini (2006) como um dos princípios da influência em seus estudos sobre a psicologia da concordância. 
A contribuição teórica é um tipo de argumento que reflete o avanço teórico da área, por exemplo, quando: (1) expande a literatura científica existente, conforme recomendado por Pendergast (2007), Mattos (2008) e Barral (2016); (2) origina novos conhecimentos, conforme atestado por Borges (2013), Santos, Kienen e Castineira (2015) e Volpato (2017); (3) contribui em termos empíricos, em alinhamento com Meruane e Balin (2012) quando mencionam a justificativa do tipo corroboração empírica de uma teoria e (4) promove a discussão ou o debate entre pesquisadores, como proposto por Ferreira (2015).

O tipo de argumento necessidade está associado com a de importância do estudo. Esse tipo de argumento foi chamado por Meruane e Balin (2012) de justificativa "baseada na importância da questão". De acordo com os autores, esse tipo de argumento ficou em segundo lugar na argumentação utilizada nas Ciências Sociais. Mostrar a importância de se fazer o estudo também se alinha com o recomendado por Figueiredo (2008), Cajueiro (2015) e Cooper e Schindler (2016). Desta forma, foram utilizadas duas estratégias: (1) mencionar explicitamente na justificativa as palavras "importância" ou "necessidade" e (2) apropriar-se de conectivos frasais (curtos ou longos) para designar necessidade.

A contribuição prática é o tipo de argumento que está ligado à contribuição gerencial e social no sentido de solucionar problemas, fomentar desenvolvimentos e aprimorar processos para a sociedade. Esse tipo de argumento foi chamado por Meruane e Balin (2012) de "baseado na contribuição dos achados", isto é, segundo Santos, Kienen e Castineira (2015), trata-se de indicar os benefícios para a sociedade de produzir ou os riscos de não produzir conhecimentos acerca do fenômeno a ser estudado. Esse tipo de argumento é o predominante nas Ciências Sociais (MERUANE e BALIN, 2012). Vale ressaltar que Vasconcelos (2009) também encontrou esse tipo de justificativa em seus estudos.

Por fim, lacuna é o tipo de argumento que mostra que existe um gap na literatura científica, um vazio de conhecimento onde o novo pode se instalar. Logo, o novo não traz apenas descobertas radicais e revolucionárias, mas também as incrementais (em algum grau diferente) (SANTOS; 
KIENEN; CASTINEIRA, 2015). Assim, como há várias formas de variação dos estudos, a lacuna pode estar, por exemplo, na metodologia (MERUANE e BALIN, 2012), no quadro teórico, no delineamento de pesquisa, nos dados e nas técnicas de coleta e análise de dados. Portanto, o novo pode ser encontrado quando o pesquisador flexibiliza a visão do mundo. 


\section{CONSIDERAÇÕES FINAIS}

Esta pesquisa exploratória apoiou-se na triangulação concomitante e procurou aliar as forças das abordagens quantitativas e qualitativas, por meio, respectivamente, da Classificação Hierárquica Descendente e da Análise de Conteúdo com o objetivo de identificar os tipos de argumentos empregados para justificar as pesquisas científicas em Administração. Para obter a resposta, teve como fonte de dados os 33 artigos selecionados para premiação no congresso EnANPAD 2016, o segundo maior evento do gênero no mundo.

Inicialmente, ratificou-se que o título, o resumo e a introdução de um trabalho científico são os principais espaços nos quais o pesquisador deve envidar todos os esforços no sentido de aprimorar o conteúdo, trazendo o leitor/avaliador para prosseguir na caminhada da análise do trabalho submetido.

Ademais, foram identificadas seis categorias que representam os tipos de argumentos empregados por artigos na área de administração: argumentos de autoridade, escassez, contribuição teórica, necessidade, contribuição prática e lacuna. Além disso, constatou-se que tanto nos artigos vencedores das divisões quanto no artigo vencedor do congresso EnANPAD 2016 predominou o tipo de argumento: argumentos de autoridade.

No que tange as divisões do EnANPAD 2016, os tipos de argumento predominantes foram: ADI - Administração da Informação com argumentos de autoridade; APB - Administração Pública com argumentos de autoridade e escassez; CON - Contabilidade com contribuição teórica; EOR - Estudos Organizacionais com contribuição teórica; EPQ - Ensino e Pesquisa em Administração e Contabilidade com contribuição teórica; ESO Estratégia em Organizações com contribuição teórica; FIN - Finanças com argumentos de autoridade; GCT - Gestão de Ciência, Tecnologia e Inovação com argumentos de autoridade e contribuição prática; $\mathrm{GOL}$ - Gestão de Operações e Logística com escassez; GPR - Gestão de Operações e Relações de Trabalho com escassez e MKT - Marketing com escassez e necessidade. 
Evidentemente, a limitação da pesquisa foi circunscrever o corpus de análise aos artigos indicados para premiação no EnANPAD 2016. Essa escolha foi justificada anteriormente, mas reconhece-se que existe a possibilidade de alguma característica específica desse congresso ter enviesado os resultados.

Como trabalho futuro, sugere-se replicar a pesquisa em outros corpus de análise envolvendo artigos de periódicos, artigos de outros congressos, dissertações e teses da área de Administração, tanto no âmbito brasileiro quanto internacional. Tais estudos podem adicionar novos tipos de argumentos ou agregar novos significados aos encontrados neste estudo.

Por fim, espera-se que esta pesquisa fomente a discussão a respeito da importância do uso de argumentação consistente como meio para melhor aceitação dos trabalhos no contexto científico e na sociedade em geral. 


\section{REFERÊNCIAS}

ABBAGNANO, N. Dicionário de filosofia. 6. ed. São Paulo: Editora WMF Martins Fontes, 2012.

ASSOCIAÇÃO NACIONAL DE PÓS-GRADUAÇÃO E PESQUISA EM ADMINISTRAÇÃO (ANPAD). Apresentação. Disponível em:

[http:/ / www.anpad.org.br/ anpad/ eventos.php?cod_evento=1\&cod_evento_edicao $=89 \#$. Acesso em: 16 de dezembro de 2018 .

BACHARACH, S. Organizational theories: some criteria for evaluation. Academy of Management Review, v. 14, n. 4, p. 496-515, 1989.

BARDIN, L. Análise de Conteúdo. 4. ed. Lisboa: Edições 70, 2011.

BARRAL, W. Metodologia da pesquisa jurídica. 5. ed. Florianópolis: Fundação Boitex, 2016.

BERTERO, C.; ALCADIPANI, R.; CABRAL S.; FARIA A.; ROSSONI, L. Os desafios da produção de conhecimento em Administração no Brasil. Cadernos EBAPE, v. 11, n. 1, p. 181-196, 2013.

BORGES, R. C. B. Como escrever um projeto de pesquisa? Revista de Metodologia da Pesquisa em Direito, v. 7, n. 1, p. 1-29, 2013.

CAJUEIRO, R. L. P. Manual para elaboração de trabalhos acadêmicos: guia prático do estudante. 3. ed. Petrópolis: Vozes, 2015.

CAMARGO, B. V.; JUSTO, A. M. IRAMUTEQ: um software gratuito para análise de dados textuais. Temas em Psicologia, v. 21, n. 2, p. 513-518, $2013 \mathrm{a}$.

CAMARGO, B. V.; JUSTO, A. M. Tutorial para o uso do software de análise textual IRAMUTEQ. Laboratório de Psicologia Social da Comunicação e Cognição - LACCOS. 2013 b. Universidade Federal de Santa Catarina. Disponível em: [http:/ /www.iramuteq.org/ documentation/fichiers/tutoriel-en-portugais]. Acesso em: 16 de dezembro de 2018.

CIALDINI, R. B. O poder da persuasão: você pode ser mais influente do que imagina. Tradução por Marcello Lino. Rio de Janeiro: Elsevier, 2006.

COOPER, D.R.; SCHINDLER, P. S. Métodos de pesquisa em Administração. Tradução por Luciana de Oliveira da Rocha. 12. ed. Porto Alegre: Bookman, 2016.

CRESWELL, J. W. Projeto de pesquisa: métodos qualitativo, quantitativo e misto. 3. ed. Porto Alegre: Artmed, 2010.

DANG, V. H. A mixed method approach enabling the triangulation technique: case study in Vietnam. World Journal of Social Science, Salvador, v. 2, n. 2, p. 1-13, 2015.

FALASTER, C. D.; FERREIRA, M. A. S. P.; CANELA, R. Motivos de rejeição dos artigos nos periódicos de Administração. Revista Organizações \& Sociedade, Salvador, v. 23, n. 77, p. 285-306, 2016. 
FERREIRA, M. P. Pesquisa em Administração e ciências sociais aplicadas: um guia para a publicação de artigos acadêmicos. Rio de Janeiro: LTC, 2015.

FERREIRA, M. P.; PINTO, C. F.; BELFORT, A. C. O que é uma boa revisão de artigo em administração. Revista Eletrônica de Estratégia \& Negócios, v. 9, n. 2, p. 87-105, 2016.

FIGUEIREDO, N. M. A. Método e metodologia na pesquisa científica. São Caetano do Sul: Yendis, 2008.

GIL, A. C. Como elaborar projetos de pesquisa. 5. ed. São Paulo: Atlas, 2010.

GRANT, J; BRUTSCHER, P. B; KIRK, S. E.; BUTLER, L. WOODING, S. Capturing research impacts: a review of international practice. Santa Monica: RAND Corporation, 2009. Disponível em: http:/ / www.rand.org/content/dam/rand/pubs/documented_ briefings/2010/RAND_DB578.pdf. Acesso em: 16 de dezembro de 2018 .

HADDAD, N. Metodologia de estudos em ciências da saúde: como planejar, analisar e apresentar um trabalho científico. São Paulo: Roca, 2004.

HUSSEIN, A. The use of triangulation in social sciences research: can qualitative and quantitative methods be combined? Journal of Comparative Social Work, p. 1-12, 2009.

KOCH, I. V.; ELIAS, V. M. Escrever e argumentar. São Paulo: Contexto, 2017.

LAKATOS, E. M.; MARCONI, M. A. Fundamentos de metodologia científica. 8. ed. São Paulo: Atlas, 2017.

MASCARENHAS, A. O.; ZAMBALDI, F.; MORAES, E. A. Rigor, relevância e desafios da academia em Administração: tensões entre pesquisa e formação profissional. RAE-revista de Administração de empresas, v. 51, n. 3, p. 265-279, 2011.

MATTOS, P. Nós e os índices: a propósito da pressão institucional por publicação. RAE revista de Administração de empresas, v. 48, n. 2, p. 144- 149, 2008.

MELLO, M. A. R. Sobrevivendo na ciência: um pequeno manual para a jornada do cientista. Belo Horizonte: Amazon, 2017.

MERUANE, O. S.; BALIN, D. L. Descripción de las formas de justificación de los objetivos en artículos de investigación en español de seis áreas científicas. Onomázen, v. 25, n. 1, p. 315-344, 2012.

MINAYO, M. C. S. (Org.). Pesquisa social: teoria, método e criatividade. 2. ed. Rio de Janeiro: Vozes, 2016.

MITCHELL, K. M.; CLARK, A. M. Five steps to writing more engaging qualitative research. International Journal of Qualitative Methods, v. 17, p. 1-3, 2018.

MORAES, R. Análise de conteúdo. Revista Educação, v. 22, n. 37, p. 7-32, 1999.

NICOLAI, A; SEIDL, D. That's relevant! Different forms of practical relevance in management science. Organization Studies, v. 31, n. 9 e10, p. 1257-1285, 2010. 


\section{GUIMARÃES \& DEBORAH MORAES ZOUAIN}

PENDERGAST, G. The art of reviewing. International Journal of Advertising, v. 26, n. 2, p. 277-280, 2007.

REBECCA, M. Measuring the impact of research. European Journal of Marketing, v. 44, 2010.

REINERT, M. Alceste: une methologie d'analyse dês donnees textualles et une application. Bulletin de Méthodologie Sociologique, v. 28, p. 24-54, 1990.

RICHARDSON, R. J. (Org.). Pesquisa social: métodos e técnicas (3. ed). São Paulo: Atlas, 2010.

SANTOS, P. A.; KIENEN, N.; CASTINEIRA, M. I. Metodologia da pesquisa social: da proposição de um problema à redação e apresentação do relatório. São Paulo: Atlas, 2015.

SERRA, F.; FIATES, G.; FERREIRA, M. Publicar é difícil ou faltam competências? O desafio de pesquisar e publicar em revistas científicas na visão de editores e revisores internacionais. Revista de Administração Mackenzie, v. 9, n. 4, p. 32-55, 2008.

SILVA, A. H.; FOSSA, M. I. T. Análise de Conteúdo: exemplo de aplicação da técnica para análise de dados qualitativos. In: Encontro de Ensino e Pesquisa de Administração e Contabilidade (ENEPQ), Brasília, Distrito Federal, Brasil, 4, 2013.

VASCONCELOS, F. Relevância e rigor na academia. Editorial. RAE - Revista de Administração de Empresas, v. 49, n. 1, p. 5, 2009.

VERGARA, S. C. Métodos de pesquisa em Administração. 6. ed. São Paulo: Atlas, 2015.

VOLPATO, G. L. Método lógico para redação científica. 2. ed. Botucatu: Best Writing, 2017.

WALDEMAR, P. J.; PEREIRA, V. L. D. V.; FILHO, H. V. P. Pesquisa cientifica sem tropeços: abordagem sistêmica. São Paulo: Atlas, 2007.

WHETTEN, D. What constitutes a theoretical contribution? Academy of Management Review, v. 14, n. 4, p. 490-495, 1989.

ZAPPELLINI, M. B.; FEUERSCHUTTE, S. G. O uso da triangulação na pesquisa brasileira em administração. Administração: Ensino e Pesquisa, v. 16, n. 2, p. 241-273, 2015. 


\section{ANEXO A}

Os 33 artigos selecionados para concorrer a premiação no congresso EnANPAD 2016. Os artigos foram numerados para facilitar a referência aos trechos de texto escolhidos para ilustrar os tipos de argumento.

Artigo 1:

CARDOSO, R. L.; LEITE, R. DE O.; AQUINO, A. C. B. The effect of cognitive reflection on the efficacy of impression management: an approach with financial analysts. ENANPAD, 40, 2016. Anais...Costa do Sauípe - BA: ANPAD, 2016.

Artigo 2:

CARNEIRO, A. DE T. A pesquisa com documentos históricos em Estudos Organizacionais: Reflexões e Experiências. ENANPAD, 40, 2016. Anais...Costa do Sauípe - BA: ANPAD, 2016.

Artigo 3:

CRUZ, A. F. DA; KIMURA, H. Title : A bird in the hand is not worth two in the bush: insider ownership, idiosyncratic risk, and cash holdings. ENANPAD, 40, 2016. Anais... Costa do Sauípe - BA: ANPAD, 2016.

Artigo 4:

DINIZ, E. H.; FAVARETTO, J. E. R.; PONTOS, H.; BRÓLIO, D. V. R. Inserção internacional do campo de administração da informação (adi): análise da formação, publicação e participação em redes de pesquisa. ENANPAD, 40, 2016. Anais...Costa do Sauípe - BA: ANPAD, 2016.

Artigo 5:

DIOGO, O. A.; VARGAS, E. R. DE; WANKE, P. F. O problema de alinhamento de territórios: uma possível aplicação às clínicas da família. ENANPAD, 40, 2016. Anais...Costa do Sauípe - BA: ANPAD, 2016.

Artigo 6:

FERREIRA, A. C.; PIMENTA, M. L.; WLAZLAK, P. G. Proposition and Validation of a Model to Measure the Level of Cross-Functional Integration Between Marketing, Logistics and Production. ENANPAD, 40, 2016. Anais...Costa do Sauípe - BA: ANPAD, 2016.

Artigo 7:

FILHO, R. N. L.; SOUZA, A. A. C.; D’SOUZA, M. F. Narcissistic personality traits in the context of accounting education: an application of the item response theory. ENANPAD, 40, 2016. Anais...Costa do Sauípe - BA: ANPAD, 2016. 


\section{GUIMARÃES \& DEBORAH MORAES ZOUAIN}

Artigo 8:

FISCHER, B. B.; GAMARRA, J. T. Moderating effects of institutional quality on the efficiency of laggard innovation systems. ENANPAD, 40, 2016. Anais...Costa do Sauípe - BA: ANPAD, 2016.

Artigo 9:

FORTUNATO, G.; DAMASCENO, R. S.; BASTOS, S. A. P. Valor de empresa: a influência da propaganda nos periodos de recessão. ENANPAD, 40, 2016. Anais...Costa do Sauípe - BA: ANPAD, 2016.

Artigo 10:

FRANCO, D. S.; NILLES, D. S. O. Atitudes retaliatórias de jovens trabalhadores: reflexões de uma análise qualitativa. ENANPAD, 40, 2016. Anais...Costa do Sauípe - BA: ANPAD, 2016.

Artigo 11:

FURTADO, L. MAGALHÃES, G. P.; SOBRAL, F. The role of causal attributions in leader-member exchange (LMX) development: a conceptual proposal for the integration of LMX and Attribution Theories. ENANPAD, 40, 2016. Anais...Costa do Sauípe - BA: ANPAD, 2016.

Artigo 12:

GUIDO, A. L. B.; JOÃO, B. N. User-generated content em serviços: uma análise do Aeroporto Internacional de Guarulhos (GRU). ENANPAD, 40, 2016. Anais...Costa do Sauípe - BA: ANPAD, 2016.

Artigo 13:

HERNANDEZ, J. M. C.; STRANO, M. P. V.; PONTOES, L. D.; CARVALLO, D. S. Overcoming consumer advertising skepticism. ENANPAD, 40, 2016. Anais...Costa do Sauípe - BA: ANPAD, 2016.

Artigo 14:

JOIA, L. A.; ALTIERI, D.; MEDEIROS, A. C. Antecedentes da intenção de uso de aplicativos móveis de táxi. ENANPAD, 40, 2016. Anais...Costa do Sauípe - BA: ANPAD, 2016.

Artigo 15:

JU, S. Y.; XAVIER, W. G. How do manufacturing firms in emerging economies become exporters? ENANPAD, 40, 2016. Anais...Costa do Sauípe - BA: ANPAD, 2016.

Artigo 16:

LACERDA, C. O.; CARVALHO, M. M. L.; VIEIRA, R. S. G. A requalificação do cais mauá e o direito à cidade: a luta pelo espaço entre conflitos, discursos e r[existência]. ENANPAD, 40, 2016. Anais...Costa do Sauípe - BA: ANPAD, 2016. 
Artigo 17:

LOCH, M.; SILVA, A. L. P. A influência do governo, como regulador e acionista, no desempenho das empresas brasileiras de distribuição de energia elétrica. ENANPAD, 40, 2016. Anais... Costa do Sauípe - BA: ANPAD, 2016.

Artigo 18:

MACHADO, D. P.; RAMOS, C. P. R.; PEIXE, B. C. S. Conexões políticas e oportunismo na gestão dos recursos públicos dos estados brasileiros: um estudo à luz da teoria dos ciclos político-orçamentários. ENANPAD, 40, 2016. Anais... Costa do Sauípe - BA: AN$\mathrm{PAD}, 2016$.

Artigo 19:

MEDEIROS, C. R.; SILVEIRA, R. A.; OLIVEIRA, L. B. "Nós estamos fazendo o que deve ser feito", "nós não colocamos a sociedade e o meio-ambiente em risco" e "a culpa não é nossa": desengajamento moral em um crime corporativo. ENANPAD, 40, 2016. Anais... Costa do Sauípe - BA: ANPAD, 2016.

Artigo 20:

MONTENEGRO, M. R.; ALBUQUERQUE, P. H. M. Gerenciamento de riqueza: modelando a dependência não linear. ENANPAD, 40, 2016. Anais...Costa do Sauípe - BA: ANPAD, 2016.

Artigo 21:

NODARI, F.; OLIVEIRA, M.; BALLE, A. R.; CORDEIRO, M. M. A miscibilidade de capacidades de ordem superior e desempenho organizacional. ENANPAD, 40, 2016. Anais... Costa do Sauípe - BA: ANPAD, 2016.

Artigo 22:

NOVA, S. P. C.; LOURENÇO, I. AZEVEDO, R. F. L. Who gives the most? trade-offs between academic success perceptions in a process of institutional change. ENANPAD, 40, 2016. Anais...Costa do Sauípe - BA: ANPAD, 2016.

Artigo 23:

PEREIRA, C. E. C.; BOAVENTURA, J. M.; TODEVA, E.; ARMANDO, E. Análise da competitividade de clusters sob a perspectiva da abrangência de negócios e especialização das empresas utilizando uma metodologia para mapeamento de clusters. ENANPAD, 40, 2016. Anais... Costa do Sauípe - BA: ANPAD, 2016.

Artigo 24:

REIS, P. R. C.; CABRAL, S. Para além dos preços contratados: uma análise da celeridade nas entregas de compras públicas eletrônicas. ENANPAD, 40, 2016. Anais... Costa do Sauípe - BA: ANPAD, 2016. 


\section{GUIMARÃES \& DEBORAH MORAES ZOUAIN}

Artigo 25:

REZENDE, L.; OLIVEIRA, J. S.; MENDES, E. Compreendendo o corpo a partir das práticas organizativas: etnografia de uma organização artesanal na cidade de Goiás, Goiás. ENANPAD, 40, 2016. Anais...Costa do Sauípe - BA: ANPAD, 2016.

Artigo 26:

SANTOS, D. B.; NORVILITIS, J.; ONUSIC, L. M.; PROTIN, P. Present parents induce responsible behavior in young people with regard to the use of credit : a comparison between the United States, France and Brazil. ENANPAD, 40, 2016. Anais...Costa do Sauípe - BA: ANPAD, 2016.

Artigo 27:

SANTOS, R. P.; JOIA, L. A. O papel da tecnologia da informação e comunicação na inclusão financeira da população ribeirinha da ilha de marajó. ENANPAD, 40, 2016. Anais... Costa do Sauípe - BA: ANPAD, 2016.

Artigo 28:

SANTOS, G. T.; SILVA, A. B. Concepções de Ser Docente na Administração. ENANPAD, 40, 2016. Anais...Costa do Sauípe - BA: ANPAD, 2016.

Artigo 29:

SAUERBRONN, F. F.; AYRES, R. M.; LOURANÇO, R. L. Perspectivas Pós-Coloniais e Decoloniais: uma proposta de agenda de pesquisa em Contabilidade no Brasil. ENANPAD, 40, 2016. Anais...Costa do Sauípe - BA: ANPAD, 2016.

Artigo 30:

SILVEIRA, R. A.; MEDEIROS, C. R. O. O herói-envergonhado: tensões e contradições no cotidiano do trabalho policial. ENANPAD, 40, 2016. Anais...Costa do Sauípe - BA: ANPAD, 2016.

Artigo 31:

SOUZA, D. L.; CASTRO, C. C. Grupos de pesquisa e desempenho inovador: um estudo exploratório a partir do diretório dos grupos de pesquisa no Brasil. ENANPAD, 40, 2016. Anais...Costa do Sauípe - BA: ANPAD, 2016.

Artigo 32:

TEIXEIRA, J. A.; RÊGO, M. C. B.; FILHO, A. I. S. Inovação em serviços no judiciário: um estudo sobre os efeitos da coprodução e das competências nos resultados da mediação judicial em um Tribunal de Justiça. ENANPAD, 40, 2016. Anais...Costa do Sauípe BA: ANPAD, 2016.

Artigo 33:

OLIVEIRA, C. B.; FILHO, J. R. F. Problemas de agência no setor público: o papel dos intermediadores da relação entre poder central e unidades executoras. ENANPAD, 40, 2016. Anais...Costa do Sauípe - BA: ANPAD, 2016. 


\section{DADOS DOS AUTORES}

\section{ALESSANDRO PRUDÊNCIO LUKOSEVICIUS alessanpl@gmail.com}

Doutor em Engenharia pela UFF

Instituição de vinculação: Universidade do Grande Rio

Rio de Janeiro/RJ - Brasil

Áreas de interesse em pesquisa: Gerenciamento de Projetos.

Rua da Lapa, 86 Centro Rio de Janeiro/RJ 20021-180

\section{JAIRO DE CARVALHO GUIMARÃES jairoguimaraes@ufpi.edu.br}

Doutor em Educação pela UFRJ

Instituição de vinculação: Universidade Federal do Piauí

Floriano/PI - Brasil

Áreas de interesse em pesquisa: Empreendedorismo; Educação Empreendedora; Gestão Ambiental; Sustentabilidade; Currículo.

\section{DEBORAH MORAES ZOUAIN deborahzouain@gmail.com}

Doutora em Engenharia da Produção pela UFRJ

Instituição de vinculação: Universidade do Grande Rio

Rio de Janeiro/RJ - Brasil

Áreas de interesse em pesquisa: Empreendedorismo; Turismo; Segurança Pública. 